ACTA UNIVERSITATIS WRATISLAVIENSIS No 3928

Slavica Wratislaviensia CLXXI • Wrocław 2020

DOI: $10.19195 / 0137-1150.171 .5$

Data przesłania artykułu: 22.10 .2018

Data akceptacji artykułu: 25.02.2019

\title{
NATALYA DIDENKO
}

Uniwersytet Wrocławski, Polska

\section{Некоторые особенности перевода мультипликационного фильма Маша и медведь на польский язык}

Аудиовизуальное произведение представляет собой полисемиотический код, состоящий из двух основных рядов: звукового и визуального, которые неразрывно связаны между собой и несут информацию как вербального, так и невербального характера. Сосуществование нескольких семиотических систем предполагает их взаимоподчинение. В связи с этим перевод аудиовизуального произведения является особым видом перевода. На это указывали в Польше Тереса Томашкевич (Teresa Tomaszkiewicz)1, Аркадиуш Бельчик (Arkadiusz Belczyk) $^{2}$, Лукаш Богуцки (Lukasz Bogucki) ${ }^{3}$, Михал Гарцаж (Michał Garcarz) $^{4}$, Пшемыслав Яниковски (Przemysław Janikowski) ${ }^{5}$, Ивона Сикора (Iwona Sikora) ${ }^{6}$, в России — Вера Евгеньевна Горшкова ${ }^{7}$, Марина

${ }^{1}$ T. Tomaszkiewicz, Przekład audiowizualny, Warszawa 2006, s. 73-74.

2 A. Belczyk, Tlumaczenie filmów, Wydawnictwo dla Szkoły, Wilkowice 2007, s. 6-7.

${ }^{3}$ Ł. Bogucki, The Constraint of Relevance in Subtitling, 2004, https://www.jostrans.org/issue01/art_bogucki_en.php [dostup: 20.08.2018].

${ }^{4}$ M. Garcarz, Przekład slangu w filmie, Kraków 2007, s. 118.

${ }^{5}$ P. Janikowski, Dobry polski Szrek. Wrażliwość kulturowa tlumacza w rękach magnatów popkultury, [w:] Kultura popularna a przektad, red. P. Fast, Katowice 2005, s. 41.

${ }^{6}$ I. Sikora, Dubbing filmów animowanych: strategie translatorskie w polskim dubbingu anglojęzycznych filmów animowanych, Nysa 2013, s. 20.

7 V. E. Gorškova, Perevod v kino: dublirovanie vs. subtitry (na materiale fil'ma Lûka Bessona „Angel.A ” Franciâ, 2005 g.), „Vestnik Novosibirskogo gosudarstvennogo universiteta. Seriâ: Lingvistika i mežkul'turnaâ kommunikaciâ" 2007, № 5, s. 134-135. 
Сергеевна Снеткова ${ }^{8}$, Евгения Дмитриевна Маленова ${ }^{9}$, Роман Александрович Матасов ${ }^{10}$ и другие.

Е. Д. Маленова в статье Теория и практика аудиовизуального перевода: отечественный и зарубежный опыт дает комплексное определение понятия „,аудиовизуальный перевод”. По ее мнению, это процесс

декодирования и передачи вербального компонента полисемиотического единства аудиовизуального произведения, в результате которого создается новый вербальный компонент этого единства, пригодный к дальнейшей обработке (субтитрированию, озвучиванию, локализации и т. п.) с учетом общего контекста произведения, ожидаемой реакции потребителя контента и функциональных ограничений, накладываемых каждым отдельным видом дальнейшей обработки ${ }^{11}$.

Анимационный фильм как разновидность аудиовизуальных произведений также отличается полисемиотичностью, что накладывает на процесс его перевода ограничения технического и функционального характера.

Стоит отметить, что в контексте аудиовизуальных продукций в Польше особое место занимают мультфильмы. Если в России достаточно большое количество зарубежных художественных фильмов подвергаются полному дублированию, то в Польше подобная техника применяется в основном к продуктам, потребителем которых являются дети. Для фильмов же используются либо субтитры, либо закадровый голос, который накладывается на слегка приглушенную оригинальную звуковую дорожку. Данный факт выводит перевод анимационных фильмов на особый уровень по сравнению с переводом других аудиовизуальных произведений.

Зарубежные мультфильмы, которые в последние годы появлялись на польских киноэкранах, как правило, американского производства. Об этом также писал П. Яниковски:

Porozmawiajmy o filmach dubbingowanych; głównie animowanych, głównie w konwencji bajkowej i głównie amerykańskich, bo thumaczenia takich właśnie cieszą się rosnącą $\mathrm{w}$ zastraszającym tempie popularnością... ${ }^{12}$

В связи с такой „монополией” американских аниматоров на польском мультипликационном рынке особым событием было в 2014 году официаль-

${ }^{8}$ M. S. Snetkova, Lingvostilističeskie aspekty perevoda ispanskih kinotekstov: na materiale russkih perevodov hudožestvennyh fil'mov L. Bunûèla , Viridiana” i P. Al'modovara ,Ženŝiny na grani nervnogo sryva", Avtoreferat dissertacii na soiskanie naučnoj stepeni kandidata filologičeskih nauk, Moskva 2009.

${ }^{9}$ E. D. Malenova, Teoriâ i praktika audiovizual'nogo perevoda: otečestvennyj i zarubežnyj opyt, „Kommunikativnye issledovaniâ” 2017, № 2, s. 34, https://cyberleninka.ru/article/n/teoriya-i-praktika-audiovizualnogo-perevoda-otechestvennyy-i-zarubezhnyy-opyt [dostup: 02.02.2018].

${ }^{10}$ R. A. Matasov, Perevod kino/video materialov: lingvokul'turologičeskie i didaktičeskie aspekty, Avtoreferat dissertacii na soiskanie naučnoj stepeni kandidata filologičeskih nauk, Moskva 2009.

${ }^{11}$ E. D. Malenova, Teoriâ i praktika..., s. 34.

12 P. Janikowski, Dobry polski Szrek..., s. 39.

Slavica Wratislaviensia 171, 2020

(C) for this edition by CNS 
ная премьера российского мультфильма Маша и медведь. Перевод данного анимационного фильма и его функционирование в польском медиапространстве имеет свои особенности. Мы попытаемся их продемонстрировать посредством анализа четырех видов канала передачи информации в аудиовизуальном произведении.

И. Сикора в книге Dubbing filmów animowanych упоминает 4 вида канала, через которые происходит трансфер информации: визуально-невербальный, акустическо-невербальный, визуально-вербальный, акустическо-вербальный ${ }^{13}$. Остановимся на каждом из них ${ }^{14}$.

\section{1. Визуально-невербальный канал}

Собирательный образ сказочного мира, представленный в мультфильме Маша и медведь, сформирован на базе русских культурных реалий, а также стереотипных представлений о русском человеке. Указывают на это элементы, отсылающие зрителя к русскому фольклору: 1) медведь, прирученный и дружелюбный, как неизменный символ России, а также один из центральных персонажей народных сказок; 2) образ девочки Маши, которая, несмотря на окружающие ее современные реалии, одета в традиционную русскую народную одежду. Кроме фольклорных элементов, на факт, что место действия - глубинка России, указывают следующие компоненты видеоряда:

1) предметы быта: самовар, стиральная доска, печка-буржуйка, раскладушка, навесной рукомойник, валенки и многое другое;

2) предметы передвижения: машина скорой медицинской помощи с соответствующей надписью и номером телефона „03” (даже в англоязычной версии);

3) пищевые продукты: сгущенка в распознаваемой упаковке, самодельное варенье, любительская колбаса и некоторые другие;

4) элементы архитектуры и интерьера: самодельный душ, вынесенный на улицу, с баком, сооруженным из молоковоза; замки в виде крючков; текстиль на стенах.

Через визуально-невербальный канал зритель получает информацию об элементах русской обыденной жизни, а также русской культуры. И. Сикора подчеркивает, что в видеоряд переводчик не может вмешаться, однако представленный в нем культурный образ отсылает зрителя к конкретному месту, стране, в которой создавался фильм. В связи с этим переводчик вынужден использовать такие решения, которые не будут противоречить визуальному образу ${ }^{15}$.

${ }^{13}$ I. Sikora, Dubbing filmów..., s. 48.

14 Представленный здесь анализ касается первых 52 серий, поскольку далее нами отмечено изменение переводческой стратегии.

${ }^{15}$ Ibidem, s. 168. 


\section{2. Акустическо-невербальный канал}

Акустическо-невербальный канал - это музыкальный и шумовой ряды, представленные в аудиовизуальном произведении.

И. Сикора подчеркивает:

Dźwięk dodaje pełni, podkreśla i akcentuje istotne elementy, buduje atmosferę i jest instrumentem wykorzystywanym do tworzenia pełnej gamy różnorodnych efektów. Synchronizacja pomiędzy warstwą akustyczną i wizualną ma niemałe znaczenie jako narzędzie do przekazania sensu i zamysłów autorów ${ }^{16}$.

В Mame u медведе функционируют два вида музыкального ряда: созданный специально для мультфильма и воспроизведенный. Информационную нагрузку в данном случае несет воспроизводимая музыка, поскольку отсылает зрителя к соответствующим знаниям. К примеру, прием аллюзии на известный фильм Иван Васильевич меняет профессию создатели Маши и медведя применили не только в видеоряде, но также и в музыкальном сопровождении, использовав вариации на известные мелодии советского фильма. Аллюзию на кинобестселлер советского времени Неуловимыле мстители передает (кроме одноименного названия серии номер 51) вариация на мелодию из этого фильма. Увертюра из советского Шерлока Холмса и доктора Ватсона гармонично дополняет серию в жанре детектива и создает соответствующий ассоциативный ряд.

Переводчик, владеющий знаниями о кинематографе народа переводимого языка, вероятнее всего, проведет надлежащие параллели и расшифрует информационный музыкальный код, однако передать результаты данной интерпретации получателю перевода не сможет. Интерфильмовость, на которую указывает (кроме всех прочих элементов) музыка, нейтрализуется естественным образом при переносе аудиовизуального произведения из культурной среды, в которой фильм создавался, в целевую среду перевода.

Таким образом, в мультипликационном фильме Маша и медведь визуально-невербальный и акустическо-невербальный каналы передают информацию, характеризующую (кроме всего прочего) культурную среду России. Причем те визуальные и акустические элементы, которые получатель перевода в состоянии однозначно соотнести с русской культурой, могут повлиять на выбор стратегии переводчика (что будет показано далее). Те же визуальные и акустические элементы, которые получатель перевода не в состоянии соотнести с конкретной культурой (хотя они являются ее показателем), нейтрализуются при восприятии аудиовизуального произведения получателем с другим когнитивным опытом.

${ }^{16}$ Ibidem, s. 68. 


\section{3. Визуально-вербальный канал}

В польском медиапространстве (интернет-пространстве) функцио-нируют две версии мультфильма Маша и медведь. Первая - на основе русскоязычного, вторая - на основе англоязычного видеорядов. То есть надписи и субтитры даны либо на русском, либо на английском языках (отметим, что официальная версия мультфильма основана на англоязычном видеоряде).

Адаптируя мультфильм Маша и медведь для польского зрителя, вполне целесообразным может показаться использование видеоряда англоязычной версии, в которой надписи и субтитры даются в знакомой для получателя перевода графической системе. Примечательно, что в одной из серий (с надписями на русском языке) в результате противоречия, которое возникло в видео- и звуковом рядах, произошел коммуникативный сбой. В серии Э прокачy! (польское название - Lekcja jazdy) Маша учит волков читать, показывает на доске буквы (конечно же кириллические) и называет их: „А”, „М”, „Р”, „У”. Последние две буквы в польском алфавите называются и произносятся иначе. В связи с этим данная сцена вызывает неоднозначную реакцию.

Стоит отметить, что подобная ситуация, в которой видеоряд противоречит звуковой канве фильма, а также его смыслу, единична, соответственно использование англоязычной версии не продиктовано крайней необходимостью. Тем более что в случае использования англоязычного видеоряда создается русско-английский образ-гибрид, вызывающий смешанное впечатление.

Следующая особенность находится на границе визуально-вербального и акустическо-вербального каналов - это трансформация визуально-вербального канала.

Посредством введения закадрового голоса в переводе мультфильма $M a-$ ша и медведь изменяется канал передачи информации с визуально-вербального на акустическо-вербальный. Необходимо отметить, что оригинальная версия мультипликационного фильма не содержит закадрового голоса, что объясняется достаточной информативностью визуального ряда, а также соответствующими репликами главной героини. В связи с этим в конечном варианте перевода нередки случаи информационной перенасыщенности.

В мультфильме Маша и медведь нами выделены три ситуации, когда закадровый комментарий является лишним (основано на классификации Роберта Макки (Robert Mckee), американского теоретика-сценариста) ${ }^{17}$ : образ.

1) Ситуация, когда закадровый комментарий дублирует визуальный

Закадровый голос: „Васh!”. Визуальный образ: доска падает на голову охотника (2 серия). Закадровый голос: „Oddamy Maszę za lodówkę”. Визуальный образ: письмо в виде рисунка медведю от волков, в котором изобра-

17 P. Orlov, Priemy: zakadrovyj golos, https:/tvkinoradio.ru/article/article13285-priemi-zakadrovij-golos [dostup: 02.02.2018]. 
жена Маша, поставлен знак равенства и изображен холодильник (5 серия). Закадровый голос: „Poczta, krzyżówki”. Визуальный образ: медведь берет из почтового ящика журнал, который открывает и зритель видит кроссворд (13 серия).

2) Ситуация, когда закадровый комментарий дублируется в реплике персонажа.

Закадровый голос: „Gamy i pasaże”. Реплика главной героини в моменте, когда медведь ставит перед ней ноты: „А na co mi gamy? Ja bez tego zagram” (19 серия). Закадровый голос: „Scenariusz”. Реплика Маши: „А co, bez scenariuszu się nie da? Inni robią bez” (42 серия). Закадровый голос: „Encyklopedia zdrowia. Czkawka. Porada pierwsza: wstrzymaj oddech na pięć minut”. Реплика главной героини: „A-a-a, oddychać, nie oddychać” (22 серия).

$3)$ Ситуация, когда закадровый голос передает большое количество информации в короткий промежуток времени.

Закадровый голос: „Wiosna, lato, jesień, zima, święta”, — звучит в течение одной-максимально двух секунд, пока на экране показывают часы медведя. Речь комментатора очень быстрая, без соответствующих пауз, не способствующая правильному восприятию информации (3 серия).

Закадровый голос: „Gdy zegar wybił północ, konie znów stały się myszami, a karoca zmieniła się z powrotem w dynię". Комментатор озвучивает текст из 3oлушки. Книга появляется в визуальном образе на пару секунд. В связи с достаточно большим отрывком текста и отсутствием времени на его произнесение комментатор заканчивает свою реплику в уже изменившимся визуальном ряду (50 серия).

Необходимо отметить, что начиная с 52 серии (На круги своя - Niełatwo wracać do doти) в польском переводе Маши и медведя закадрового голоса нет.

\section{4. Акустическо-вербальный канал}

Акустическо-вербальный канал - собственно переводной текст, над которым работает переводчик. Здесь нами выделены следующие особенности:

1) Все элементы мультфильма, которые непосредственно ассоциируются с Советским Союзом, в переводе подверглись нейтрализации посредством техники опущения либо замены без сохранения ассоциативного ряда.

Так, большинство советских песен, исполняемых главной героиней, в польском варианте опускается. В 12 серии (Граница на замке - Obrona granic) Маша в оригинальной версии поет известную военную песню Tpu танкиста. В польском переводе она отсутствует, причем нарушена связь с визуальным образом: девочка Маша представлена крупным планом и совершает движения губами на фоне тишины. Так, с целью удаления нежелательных ассоциаций нарушена корреляция видео- и звукоряда. В серии 35 (Трудно быть маленьким - Niełatwo być dzieckiem) Маша поет советскую 
песню Мари авиаторов („Все выше и выше, и выше, стремим мы полет наших птиц”), которая также пропускается в польской версии. Однако метод опущения в данном случае вполне оправдан: в этот момент в визуальном образе нет главной героини, а появляется летящий самолет. По такому же принципу (отсутствие в видеоряде персонажа, произносящего речь) пропускается несколько измененная известная советская песня $A$ я иду, шагаю по Москве. Маша в это время находится под колпаком и поет в оригинале: „А я иду, шагаю в темноте”.

Всем известная фраза Юрия Гагарина „Пять минут, полет - нормальный”, которую произносит Маша, в польском переводе звучит следующим образом: „Lot przebiega zgodnie z planem”. Реплика, которая у каждого россиянина вызовет ассоциативную связь с первым полетом человека (советского человека) в космос, в польском варианте передается нейтральным в ассоциативном плане утверждением.

Фраза „Вот и стали мы на год взрослей” взята из песни, которая впервые прозвучала в советском фильме 60-х годов прошлого столетия Прощайте, голуби! и стала крылатой. Эти слова Маша напевает в день первого сентября, что вызывает соответствующее чувство ностальгии об ушедшем детстве, школьных годах, пионерских лагерях. Очень часто эту песню исполняют на последнем звонке в школе. Переводчик сохранил семантическое содержание данного текста, однако утратил соответствующие ассоциативные связи: „O rok jesteśmy starsi” (11 серия).

2) Нейтрализация интертекстуальности реплик главной героини.

Первая строка стихотворения А. С. Пушкина Зимнее утро „Мороз и солнце; день чудесный” в польском варианте Маши и медведя переведена дословно „Mróz, słoneczko, dzień przecudny”. Известную фразу из произведения И. Ильфа и Е. Петрова Золотой теленок „Эх, прокачу!” переводчик трансформировал в нейтральное в ассоциативном плане выражение: „Моże podrzucę?”. А реплика персонажа Назарова из произведения Хаджи-Мурат Л. Толстого „Врешь, не уйдешь!” (которая также является крылатой) — и вовсе была удалена из переводного текста.

Необходимо отметить, что правильное усвоение информации интертекстуального коммуниката зависит от возраста реципиента. Несомненно, пятилетний ребенок не в состоянии будет узнать и истолковать соответствующим образом цитаты из художественной литературы, а также советские песни и аллюзии на фильмы ушедшей эпохи. Примечательно, что создатели мультфильма позиционируют его как анимационный сериал для общей аудитории, то есть как для детей, так и для взрослых. Вероятнее всего, интертекстуальность/интерфильмовость и связанные с ними ассоциативные ряды, а также комизм предназначены именно для взрослого реципиента (старшего школьника). При переводе после нейтрализации аллюзий и не замещения их подобными интертекстуальными элементами из собственной (польской) культуры взрослый получатель перевода лишается первоначальной, зало- 
женной создателями фильма информации, ассоциативных рядов и комического эффекта. Это приводит к трансформации статуса мультфильма-оригинала „для общей аудитории” в статус переведенного продукта „для детской аудитории".

3) Стратегия натурализации перевода, в данном случае - полонизации, использована лишь в случаях с крайней необходимостью.

К примеру, некоторые виды звукоподражания в русском и польском языке не совпадают. Звук мотора автомобиля в русском языке звучит как „дрын-дрын”, тогда как у польского ребенка это сочетание звуков не вызовет необходимой реакции. Соответственно, в переводной версии Маши и медведя для передачи гула мотора используется звукоподражание „brum-brum” (14 серия). Топот копыт в русской культуре выражается посредством звука „тыгыдык”, в то время как польская лошадь скачет под звук „раtataj”, что было учтено переводчиком в серии 28 (Ход конем - Ruch koniem).

Крайне странно было бы, если бы в сериях, посвященных Новому году, в польской версии мультфильма остался Дед Мороз, а не появился Святой Николай (Święty Mikołaj). В серии номер 10 игра „салочки” в польской версии трансформируется в соответствующее название, которое известно польскому ребенку, — „berek”.

\section{Выводы}

Российский анимационный фильм Маша и медведь как зарубежный продукт в польском медиапространстве является уникальным произведением. Уникальность его состоит в том, что мультфильм был создан в России, а не в Америке, которая почти „монополизировала” кинопространство не только Польши, но и многих других стран.

На основе проведенного анализа четырех каналов передачи информации в анимационном фильме Мама и медведь нами были выделены некоторые особенности перевода и функционирования мультфильма в польском медиапространстве:

1. Анимационный фильм как вид аудиовизуального произведения требует от переводчика воссоздания гармонии между всеми семиотическими системами фильма. Если в видеоряде главная героиня имеет все признаки того, что она - русская девочка, то и в звуковом вербальном плане она должна сохранить признак того, что она — представитель чуждой культуры. Однако чуждость эта не может превосходить определенные границы, которые устанавливает факт, что главным получателем перевода является ребенок. В связи с чем переводчиком в качестве ведущей стратегии выбирается стратегия нейтрализации культурного компонента в вербальном канале: пропущены либо нейтрализованы элементы, непосредственно и опосредованно отсылающие к советской эпохе, нейтрализованы аллюзии к русским литературным произведениям посредством близкого семантического перевода и одновре- 
менно утраты ассоциативной эквивалентности. Полонизация имела место только в тех случаях, когда была единственным возможным решением.

2. Переводчик подвергает трансформации только вербальный компонент аудиовизуального произведения, который выражается посредством акустического и визуального каналов. Прибегая к решению ввести в мультфильм закадровый голос, переводчик перестраивает визуально-вербальный компонент оригинала в акустическо-вербальный компонент перевода. Данный подход, вероятнее всего, был выбран в связи с возрастной характеристикой получателя перевода, однако не оправдал себя в большинстве случаев. Желание адаптировать мультфильм для восприятия ребенка привело к информационной перенасыщенности переводной версии.

3. Факт того, что в польском медиапространстве (интернет-пространстве) функционируют две версии Маши и медведя, отличающиеся графической особенностью видеоряда: англоязычная и русскоязычная, — на наш взгляд, является беспрецедентным. Выбор в пользу англоязычной версии может быть обусловлен близостью графических систем английского и польского языков, которые основаны на латинском алфавите. Однако при этом визуальный образ Маши становится неким гибридом с противоречивым видеорядом, который совмещает элементы нескольких культур.

\section{Библиография}

Belczyk A., Tłumaczenie filmów, Wydawnictwo dla Szkoły, Wilkowice 2007.

Bogucki Ł., The Constraint of Relevance in Subtitling, 2004, https://www.jostrans.org/issue01/ art_bogucki_en.php.

Garcarz M., Przektad slangu w filmie, Wydawnictwo Tertium, Kraków 2007.

Gorškova V. E., Perevod v kino: dublirovanie vs. subtitry (na materiale fil'ma Lûka Bessona „Angel.A”; Franciâ, 2005 g.), „Vestnik Novosibirskogo gosudarstvennogo universiteta”. Seriâ: Lingvistika i mežkul'turnaâ kommunikaciâ" 2007.

Janikowski P., Dobry polski Szrek. Wrażliwość kulturowa tlumacza w rękach magnatów popkultury, [w:] Kultura popularna a przekład, red. P. Fast, Wydawnictwo Śląsk, Katowice 2005.

Malenova E. D., Teoriâ i praktika audiovizual'nogo perevoda: otečestvennyj i zarubežnyj opyt, „Kommunikativnye issledovaniâ” 2017, № 2, https://cyberleninka.ru/article/n/teoriya-i-praktika-audiovizualnogo-perevoda-otechestvennyy-i-zarubezhnyy-opyt.

Matasov R. A., Perevod kino/video materialov: lingvokul'turologičeskie i didaktičeskie aspekty, Avtoreferat dissertacii na soiskanie naučnoj stepeni kandidata filologičeskih nauk, Moskva 2009.

Orlov P., Priemy: zakadrovyj golos, https://tvkinoradio.ru/article/article13285-priemi-zakadrovij-golos.

Sikora I., Dubbing filmów animowanych: strategie translatorskie w polskim dubbingu anglojęzycznych filmów animowanych, PWSZ w Nysie, Nysa 2013.

Snetkova M. S., Lingvostilističeskie aspekty perevoda ispanskih kinotekstov: na materiale russkih perevodov hudožestvennyh fil'mov L. Bunûèlâ ,, Viridiana" i P. Al'modovara ,Ženŝiny na grani nervnogo sryva", Avtoreferat dissertacii na soiskanie naučnoj stepeni kandidata filologičeskih nauk, Moskva 2009.

Tomaszkiewicz T., Przekład audiowizualny, Wydawnictwo Naukowe PWN, Warszawa 2006.

Slavica Wratislaviensia 171, 2020

(C) for this edition by CNS 


\section{Some properties of the Polish translation of the animated film Masha and the Bear}

\section{Summary}

The paper touches upon the issue of the translation into Polish of the animated film Masha and the Bear. As an audiovisual entity, the animations are characterised by polysemiotics. Therefore, four channels of information transfer were analysed: the verbal-acoustic channel, the verbal-visual channel, the acoustic-non-verbal channel and the visual-non-verbal channel. As a result of the study, it was shown that the animated film Masha and the Bear - as regards the visual-non-verbal and acoustic-non-verbal channels, can be characterised as highly reflecting the Russian culture. What was also observed was the transformation of the verbal-visual channel which - in translation changes into the verbal-acoustic channel. This transformation resulted in the information excess noticed in translation. The verbal-acoustic channel is characterised, on the one hand, by the neutralisation of intertextual and Soviet elements and, on the other hand, by a low level of the naturalisation of the Polish translation.

Keywords: audiovisual translation, polysemiotics, intertextuality, translation strategy, transformation

\section{Niektóre cechy przekładu filmu animowanego Masza i Niedźwiedź na język polski}

\section{Streszczenie}

Artykuł poświęcony jest tłumaczeniu filmu animowanego Masza i Niedźwiedź na język polski. Animacja, jako twór audiowizualny, charakteryzuje się polisemiotycznością. W związku z tym zostały zbadane cztery kanały przekazu informacji: werbalno-akustyczny, werbalno-wizualny, akustyczno-niewerbalny i wizualno-niewerbalny. Przeprowadzone badanie wykazało, że animacja $\mathrm{Ma}$ sza i Niedźwiedź na płaszczyźnie wizulano-niewerbalnej oraz akustyczno-niewerbalnej w wysokim stopniu cechuje się przynależnością do rosyjskiej kultury. Zaobserwowano transformację kanału werbalno-wizualnego, który w przekładzie zmienia się w kanał werbalno-akustyczny. To przekształcenie skutkowało nadmiarem informacji w tłumaczeniu. Kanał werbalno-akustyczny charakteryzuje się, z jednej strony, neutralizacją elementów intertekstualnych i radzieckich, z drugiej — małym stopniem naturalizacji przekładu, czyli spolszczenia.

Słowa kluczowe: przekład audiowizualny, polisemiotyczność, intertekstualność, strategia tłumaczeniowa, transformacja 